\title{
DETERMINING CONVENTION PLANNERS' PERCEPTIONS OF CONVENTION HOTEL SELECTION CRITERIA BY ANALYTIC HIERARCHY PROCESS
}

\author{
Meryem Akoğlan Kozak \\ Faculty of Business Administration \\ Anadolu University \\ Eskişehir, TURKEY \\ E-mail:mkozak@anadolu.edu.tr \\ Çağıl Hale Özel \\ Faculty of Tourism \\ Anadolu University \\ Eskişehir, TURKEY \\ E-mail: chkayar@anadolu.edu.tr \\ E. Ozan Aksöz \\ Faculty of Tourism \\ Anadolu University \\ Eskişehir, TURKEY \\ E-mail: ozana@anadolu.edu.tr
}

\begin{abstract}
Being successful in convention tourism requires conducting continuous research about the convention planners' preferences for convention hotels. Owners of such events forward their requests to convention planners and leave the full organization of convention to convention planners. For that reason, convention hotels compete fiercely with each other to attract the attention of convention planners. The aim of this study is to determine the importance rank order of convention hotel selection criteria for national and international convention planners operating in Turkey. To accomplish that aim, convention planners from 41 different provinces in Turkey were interviewed face to face via survey questionnaires. Data gathered from convention planners were analyzed with Analytic Hierarchy Process. Findings demonstrated the most and the least important criteria of convention hotel selection.
\end{abstract}

Keywords: Convention planners, Travel agencies, Convention hotel criteria, Analytic hierarchy process, Turkey. 


\section{Introduction}

Convention and meeting planners have become the key actors of convention tourism. For this reason, their demands and requirements should be carefully taken into consideration. Despite the importance of convention hotel selection in convention tourism, there has not been much research focused on finding out the most important criteria of convention hotel selection considered by convention planners. To be successful in convention tourism, it is important to understand convention planners' preferences about convention hotel selection. Therefore, an understanding of the relative importance of various convention hotel selection criteria should be of considerable interest to convention hotel managements. The aim of this study is therefore to determine the importance rank order of convention hotel selection criteria for national and international convention planners operating in Turkey. This study presents an AHP (Analytical Hierarchy Process) decision model for convention hotel selection which helps to determine the priorities of convention hotel selection criteria in convention planners' point of view. AHP is a structured method to elicit preference opinions from decision makers. Its methodological procedure can easily be incorporated into multiple objective programming formulations with interactive solution process. So that, it will be able to understand which criteria are more effective on convention planners' decisions.

Besides, it will be possible to understand the individual demands of convention planners with the help of this model. The study adopts a descriptive approach in which related studies in the literature were compiled and site selection and convention hotel selection criteria of convention planners were identified. The study consists of three sections. The first section presents a comprehensive literature review on convention site and hotel selection criteria. A description and illustration of the AHP model developed for the aim of the study follows this section. Finally, the most and the least important hotel selection criteria for convention planners are discussed.

\section{Literature Review}

In parallel with the developments in convention tourism, there are a lot of studies considering the site selection and hotel selection criteria of convention planners. In majority of these studies, authors tried to sort these site and hotel selection criteria according to the degree of importance convention planners attribute to them. The study of Crouch and Ritchie (1997) is one of the pioneering studies on determining the site selection criteria for convention planners. In this study, questions were asked to different actors of conventions (for example; convention owner, convention planners, firms, participants) to identify the factors to be considered in convention site selection. Eight important criteria have been identified such as; accessibility, local support, nonconference opportunities, accommodation facilities, meeting facilities, information, the location of the environment and other criteria. This study was referred by the majority of the subsequent literature on site and hotel selection criteria.

Baloğlu and Love (2001), focused on 23 criteria taken into account by association meeting planners and tried to determine the performances of five major convention cities in USA with regard to these criteria. Some of these criteria are as follows; capacity of meeting facilities, quality of meeting facilities, safety and security of destination, accessibility of destination, hotel room capacity, city reputation and climate. As a result of interviews with 16 planners, more and less significant criteria were determined together with the best performing-city. 
Moser (2003) examined the change in convention planners' and participants' expectations of site selection. Moser tried to determine the leading criteria used in convention planners' and participants' decision making process and also tried to specify the methods used in ordering these criteria. In gathering the site selection criteria, criteria used in studies of Crouch and Weber (2002), Crouch and Ritchie (1998), Gess (1975) and Oppermann and Chon (1997) were found to be guiding. Some of these criteria are; accessibility, local support, extra conference opportunities, accommodation facilities, meeting facilities, information, site environment and other criteria. Findings of the study showed that accessibility were found to be the most significant site selection criteria and face-to-face interview was found to be the most effective method for determining the significance of various criteria. In another study Getz (2004), classified the convention site selection criteria mentioned in previous studies under 10 headings. These are called; accessibility; supply of event venues, accommodations, amenities, image as a desirable place to visit, reputation for hosting successful events, safety and comfort of visitors, support services to events, number and type of local organizations and business and cost.

Chen (2006) conducted a study in which the aim was to propose an analytical hierarchy process (AHP) model to construct an evaluation structure with criteria and associated weights of convention site selection for meeting planners. As a result of a detailed literature review, 5 main criteria and 17 sub-criteria were identified for convention site selection and a data collection form was formed. Main criteria are; meeting and accommodation facilities, costs, site environment, local support and extra conference opportunities. A three-level hierarchical structure was performed according to the responses of 35 academic-related association directors who have hosted international conventions in 2003 in Taiwan. According to the findings of the study, meeting and accommodation facilities and site environment were found to be much more significant compared to other criteria.

To sum up, literature on the site and convention hotel selection demonstrated that large amount of research done on event planners and hotel and site selection exists. Convention and meeting planners have become the key actors of convention tourism whose demands and requirements should be carefully listened to. There is nevertheless a relatively neglected area of tourism research as no article has encompassed the hotel selection criteria of specialist convention planners operating in Turkey, who are organizing both national and international conventions all over the world. However, this information may be of importance in terms of shedding light on convention hotel selection criteria that convention planners take into account while planning national and international conventions.

\section{Hypotheses/Objectives}

One of the objectives of this study is to find out the relatively more and less important criteria of convention hotel selection with regard to convention planners. The other objective of the study is to have an opinion about the demands of convention planners while planning conventions on national and international level.

\section{Research Design/Methodology}


The data collection form used in this study was derived from the data collection forms used various studies in related literature. Some of these studies can be listed as; Crouch and Ritchie (1997), Opperman and Chon (1997), Clark, Evans and Knutson (1998), Chacko and Fenich (2000), Upchurch, Jeong, Clements and Jung (2000), Baloğlu and Love (2001), Crouch and Louviere (2004), Getz (2004), Chen (2006), Fawzy and Samra (2008), Amiri, Zandieh, Vahdani, Yazdani and Soltani (2008), DiPietro, Breiter, Rompf, Godlewska (2008), Nelson and Rys (2000), Tsai and Ho (2009), Jeon and Kim (2011) and Chiappa (2012).

Site selection and hotel selection criteria present in above mentioned studies were gathered in a pool. Then, the main criteria and sub-criteria of convention hotel selection were determined based on the views of experts. A three-step Delphi technique was employed for this aim. In each of these steps, a total of fifteen experts were consulted (five academicians, five hotel managers and five other experts from the fields of public relations, food and beverage, travel agencies, event planning). After the completion of the third step, experts came to an agreement on the main criteria and sub-criteria. More specifically, 22 sub-criteria and 5 main criteria to which these sub-criteria belong to were determined. The data collection form was given the final shape and directed to the officials of A class members of Association of Turkish Travel Agencies. There are 618 A class travel agencies operating in 41 different provinces in Turkey.

\section{Data/Model Analysis}

Below is the decision hierarchy of the model used in this study. Expert Choice Software will be used for the analysis of data in this study. 


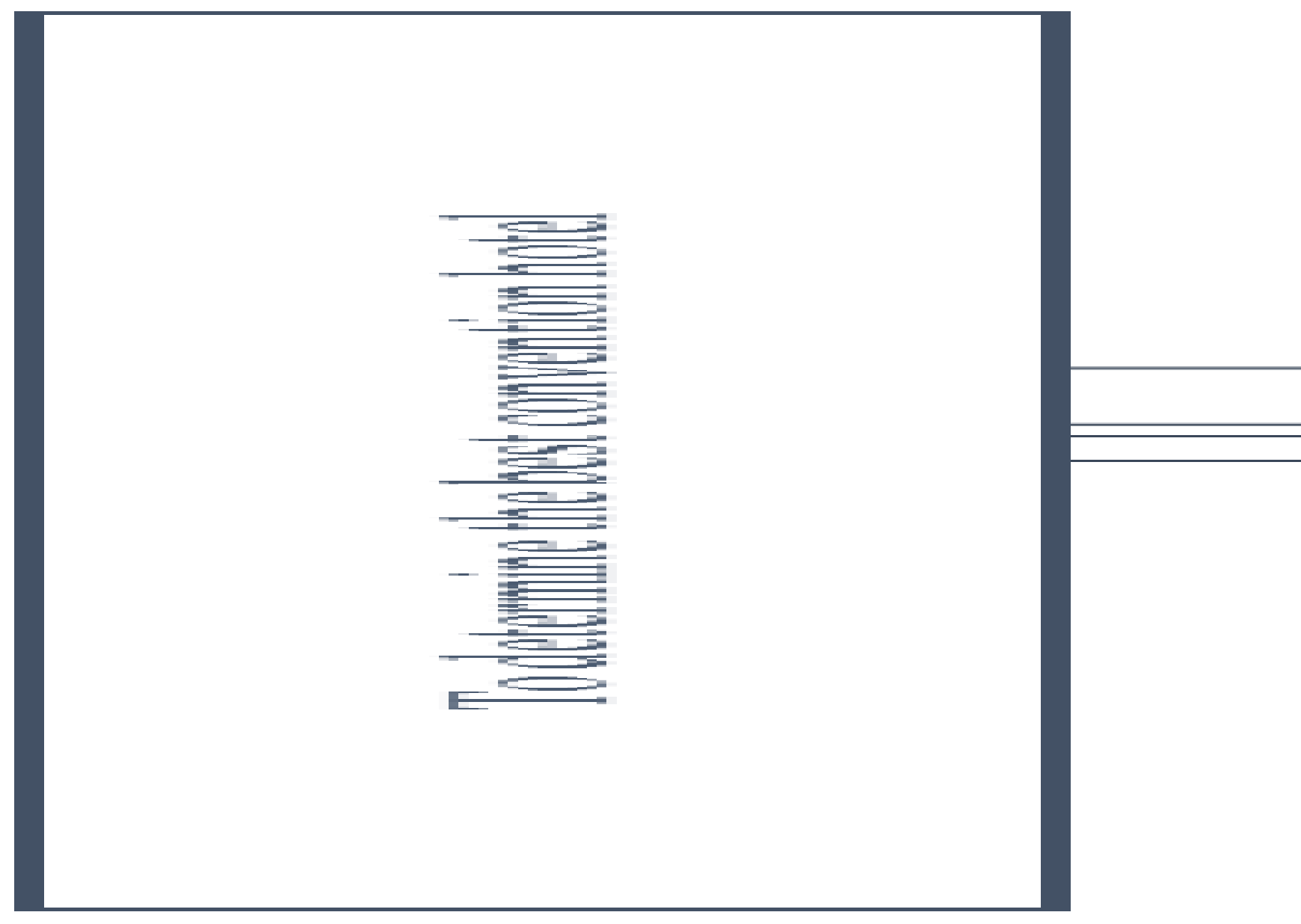

\section{Limitations}

In this study, the total list of convention planners was obtained from The Association of Turkish Travel Agencies. But it was understood that approximately one fourth of these agencies did not really exist at the time of survey. Also, the convention planners in the sample, who were reached and accepted to take part in the survey, were assumed to be experts and their pairwise comparisons were considered to be made sincerely. 


\section{Conclusions}

This study contributes to the theoretical knowledge by applying AHP to the whole population of convention planner experts in Turkey. Besides, the present study gives recent information about the importance rank order of convention hotel selection criteria in terms of convention planners in Turkey. The AHP model suggested in this study can be used as a decision making tool for convention planners to select the best convention hotel. The conclusions of the study will also help hotel managers to find out which criteria should be taken into consideration in order to compete with other convention hotels in the market.

\section{Key References}

Baloğlu, Ş. \& Love, C. (2001). Association meeting planners' perceptions of five major convention cities, Journal of Convention \& Exhibition Management, 3 (1): 21-30.

Chen, C. (2006). Applying the Analytical Hierarchy Process (AHP) approach to convention site selection, Journal of Travel Research, 45: 167-174.

Crouch, G. I. \& Richie, J. R. (1998). Convention site selection research: A review, conceptual model, and propositional framework, Journal of Convention \& Exhibition Management, 1, 1: 49-69.

Crouch, G. I. \& Ritchie, B. (1997). Convention site selection research, Journal of Convention \& Exhibition Management, 1 (1): 49-69.

Opperman, M. \& Chon, K. (1997). Convention participation decision-making process, Annals of Tourism Research, 24 (1): 178-191. 